\title{
Transvaginal ultrasound in deep endometriosis: pictorial essay
}

\author{
Ultrassonografia transvaginal na endometriose profunda: ensaio iconográfico
}

\section{Jorge Gilmar Amaral de Oliveira ${ }^{1, a}$, Vanessa Bonfada ${ }^{2, b}$, Janice de Fátima Pavan Zanella ${ }^{3, c}$, Janaina Coser ${ }^{3, d}$}

1. Promed Clínica Médica, ljuí, RS, Brazil. 2. Secretaria Municipal de Saúde de ljuí, ljuí, RS, Brazil. 3. Programa de Pós-Graduação em Atenção à Saúde - Universidade de Cruz Alta/Universidade Regional do Noroeste do Estado do Rio Grande do Sul, Cruz Alta/ljuí, RS, Brazil.

Correspondence: Dr. Jorge Gilmar Amaral de Oliveira. Promed Clínica Médica. Avenida David José Martins, 291. ljuí, RS, Brazil, $98700-000$. Email: gynosom@terra.com.br.

a. https://orcid.org/0000-0001-9558-9441; b. https://orcid.org/0000-0002-4033-3980; c. https://orcid.org/0000-0003-4678-5512; d. https://orcid.org/0000-0003-3631-0847.

Received 7 February 2018. Accepted after revision 24 April 2018.

How to cite this article:

Oliveira JGA, Bonfada V, Zanella JFP, Coser J. Transvaginal ultrasound in deep endometriosis: a pictorial essay. Radiol Bras. 2019 Set/Out;52(5): 337-341.

Abstract Endometriosis is characterized by the presence of endometrial tissue outside the uterus. When endometrial implants penetrate more than $5 \mathrm{~mm}$ into the peritoneum, the condition is referred to as deep pelvic endometriosis. Although laparoscopy is the gold standard test to establish a diagnosis of deep endometriosis, transvaginal ultrasound represents an alternative that can contribute to detection of the disease, because it is an accessible, low-cost, noninvasive examination that allows preoperative planning in cases requiring surgical treatment. However, in clinical practice, transvaginal ultrasound is still not widely used as the first-line examination in suspected cases of endometriosis. This essay describes the findings of deep endometriosis on transvaginal ultrasound, in order to disseminate knowledge of the utility of the technique for the diagnosis of this disease.

Keywords: Endometriosis/diagnostic imaging; Ultrasonography/methods; Diagnostic techniques and procedures.

Resumo A endometriose é caracterizada pela presença de tecido endometrial fora do útero. Quando os implantes endometriais penetram mais de $5 \mathrm{~mm}$ no peritônio, são definidos como endometriose pélvica profunda. 0 exame padrão ouro para estabelecer seu diagnóstico é a laparoscopia, mas a ultrassonografia transvaginal pode contribuir na detecção da doença, por ser um exame acessível, de menor custo, não invasivo e por possibilitar o planejamento pré-operatório nos casos em que é necessário o tratamento cirúrgico. Entretanto, este método como primeiro exame a ser solicitado na suspeita de endometriose precisa ser mais considerado na prática clínica. Este ensaio descreve os achados da endometriose profunda na ultrassonografia transvaginal, com o intuito de difundir a importância da técnica para o diagnóstico dessa doença.

Unitermos: Endometriose/diagnóstico por imagem; Ultrassonografia/métodos; Técnicas e procedimentos diagnósticos.

\section{INTRODUCTION}

Endometriosis has a significant impact on the quality of life of women. In addition to the characteristic symptoms (dysmenorrhea, pelvic pain, dyspareunia, urinary changes, and intestinal alterations), it causes psychological, marital, and social distress ${ }^{(1)}$.

Difficulties in the diagnosis of endometriosis are still observed in clinical practice. Therefore, it is necessary to develop techniques that are more accessible, are less invasive, and have good reproducibility ${ }^{(2)}$. Magnetic resonance imaging has long been the method of choice for the assessment of pelvic disorders ${ }^{(3-6)}$. Although laparoscopy is the gold-standard test to establish a diagnosis of deep endometriosis, transvaginal ultrasound (TVUS) can contribute to its detection, because it is an accessible, noninvasive examination that allows preoperative planning in cases requiring surgical treatment ${ }^{(7)}$.

The aim of this study was to present the main findings of deep pelvic endometriosis on TVUS. We have done so in the form of a pictorial essay.

\section{METHODS}

The findings described in the present study were obtained from surgically or histologically confirmed cases of endometriosis, selected from a study approved by the Research Ethics Committee of the Universidade de Cruz Alta and conducted at a medical clinic in the northwestern region of the Brazilian state of Rio Grande do Sul.

\section{TVUS PROTOCOL}

It has been suggested that ultrasound should be the first-line imaging method for assessing women with suspected endometriosis. However, that assessment should be carried out with standardized, well-established protocols ${ }^{(8)}$.

The ultrasound technique used was based on the protocol defined by a consensus opinion from the International Deep Endometriosis Analysis group ${ }^{(9)}$. In the first step of the examination, the uterus and adnexa were examined with a suprapubic approach, as were the bladder and kidneys. In the second step, the mobility of the uterus and ovaries was determined through the use of TVUS. The 
third step was to search for markers such as local sensitivity and fixation of the ovaries. Next, the technician looked for the "sliding sign" (the anterior rectal wall gliding freely across the posterior cervix and posterior vaginal wall when gentle pressure is applied to the cervix with the transvaginal transducer). The fourth step involved searching for hypoechoic nodules or irregularities in the anterior and posterior compartments.

All examinations were performed after bowel preparation. Gonçalves et al. ${ }^{(10)}$ recommended the use of an oral laxative on the evening prior to the examination and a sodium phosphate enema an hour before.

\section{DEEP ENDOMETRIOSIS FINDINGS IN TVUS}

According to Arruda et al. ${ }^{(7)}$, deep endometriosis is not always easily identified on TVUS, because it can present as small lesions. Because the accuracy of the examination depends on the skill of the technician, it is important that ultrasound technicians be familiar with variations in its presentation.

The present study describes lesions compatible with endometriosis, identified by TVUS at different sites, including the ovaries, intestines, posterior cervical region, round ligament, bladder, and myometrium.

\section{Endometriomas}

Endometriomas, which represent the most obvious manifestation of endometriosis on TVUS, are usually bilateral and rounded, with regular margins and a homogeneous echotexture, as well as being hypoechoic, containing diffuse areas of low echogenicity or debris ${ }^{(11)}$.

Figure 1 shows two ovarian cysts diagnosed as endometriomas. They were characterized as unilocular cystic tumors, with ground-glass echogenicity, and were found to be poorly vascularized on Doppler ultrasound.

Ovarian endometriomas constitute a warning sign that calls for a thorough evaluation of the most common sites

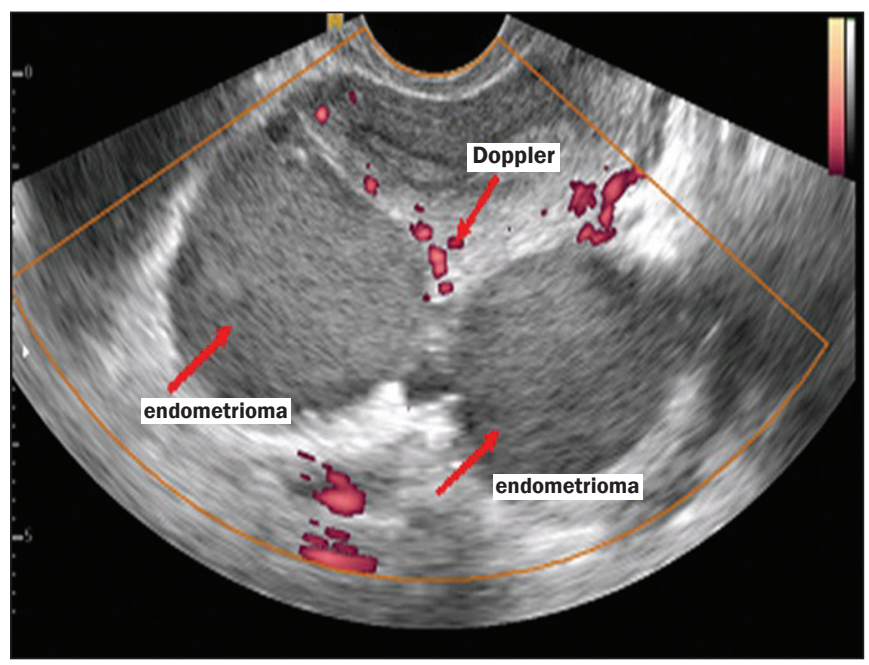

Figure 1. Posterior uterine cysts filled with keratin flakes, showing no internal vascularization on Doppler ultrasound. of deep endometriosis, because they are markers of deeper, more severe endometriosis ${ }^{(7)}$.

Figure 2 shows another ovarian endometrioma. According to Guerriero et al. ${ }^{(9)}$, such lesions can involve the entire ovary, allowing the identification of only small, usually semicircular, peripheral foci, which correspond to the residual ovarian parenchyma.

\section{Intestinal endometriosis}

Nodules or irregular hypoechoic lesions in the intestinal wall, involving the muscularis propria of the rectum or sigmoid colon can be classified as deep endometriosis with intestinal involvement ${ }^{(12)}$. However, to recognize the aspects of intestinal endometriosis on ultrasound, it is necessary to recognize the normal ultrasound aspect of the intestinal walls (Figure 3).

Gonçalves et al. ${ }^{(10)}$ define intestinal endometriosis as that which invades the muscularis propria. The criterion used by those authors to predict such involvement was the presence of a nodule or irregular hypoechoic thickening of the muscularis propria of the bowel loop, regardless of the

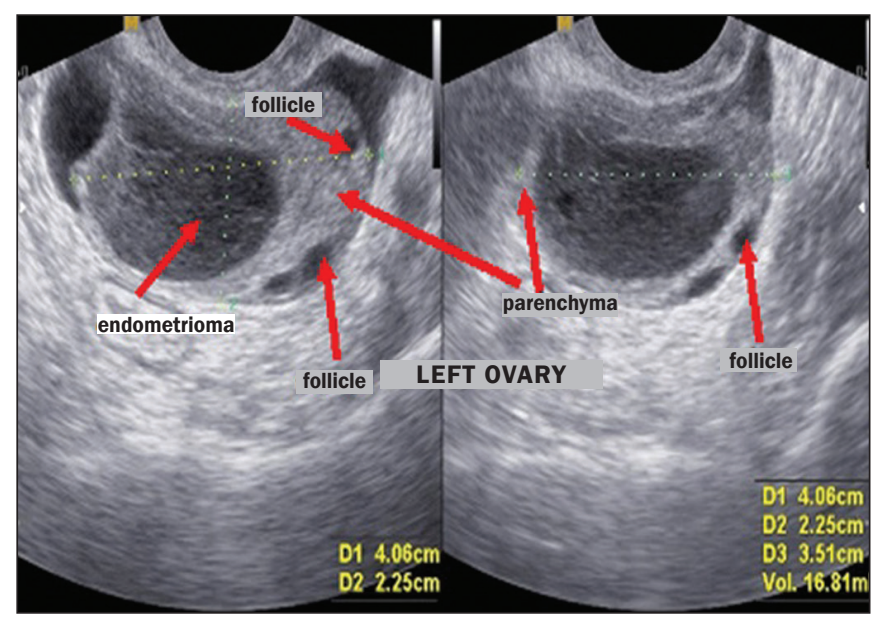

Figure 2. Endometrioma within the left ovary. Note the ovarian parenchyma with follicles at the periphery. The arrows indicate the ovarian follicles, endometrioma, and parenchyma.

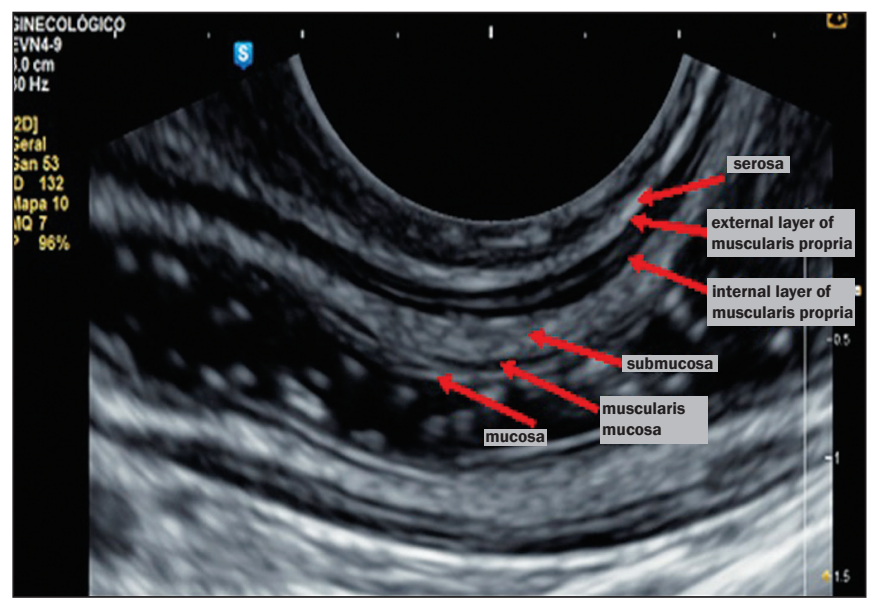

Figure 3. Sagittal TVUS image of a normal rectum, obtained after bowel preparation, showing from the outer layer to the inner layer. 
hyperechoic layer, which separates the internal and external layers of the muscularis propria, resulting in solution of continuity.

Figures 4 and 5 show the characteristic aspect of intestinal endometriosis: an irregular hypoechoic lesion.

\section{Endometriosis in the posterior cervical region}

The ultrasound aspect of deep endometriosis is a hypoechoic thickening or the presence of a nodule or mass with regular or irregular contours located in the posterior cervical region or pouch of Douglas ${ }^{(12)}$.

Figures 6 and 7 show the normal appearance of the posterior uterine serosa (continuous hyperechoic line) in longitudinal and transverse views.

In some cases, endometriosis not only infiltrates the cervix but also interrupts the serosa, as depicted in Figure 8. These situations are frequently reported in cases of deep endometriosis lesions found in the retrouterine space, in the posterior cervical region, and in the pouch of Douglas, infiltrating the wall of the vaginal fornix ${ }^{(7)}$.

Although ureteral endometriosis is a rare disease, it deserves mention here because of its nonspecific symptoms, as well as because it can silently progress to renal failure.

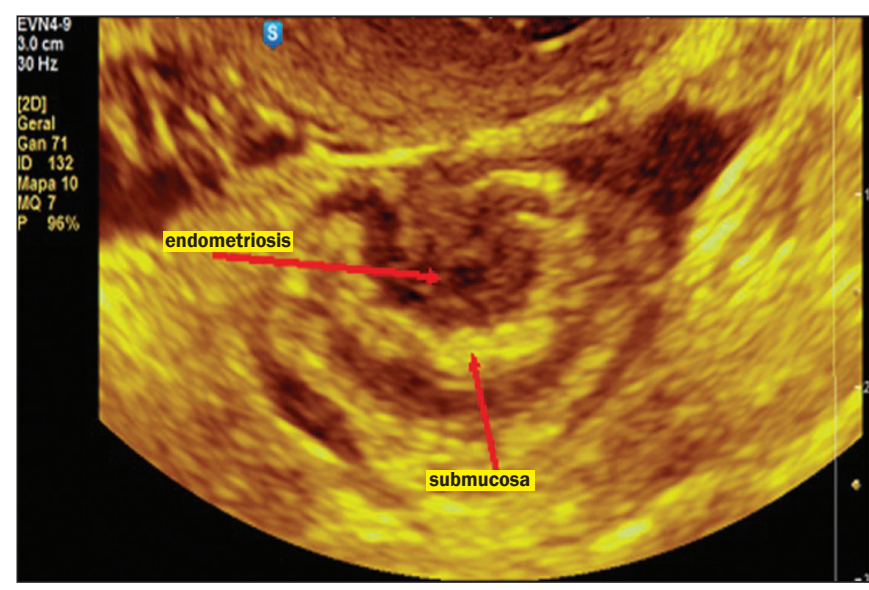

Figure 4. Typical ultrasound aspect of intestinal endometriosis (hypoechoic area) affecting the muscularis propria but not the submucosa.

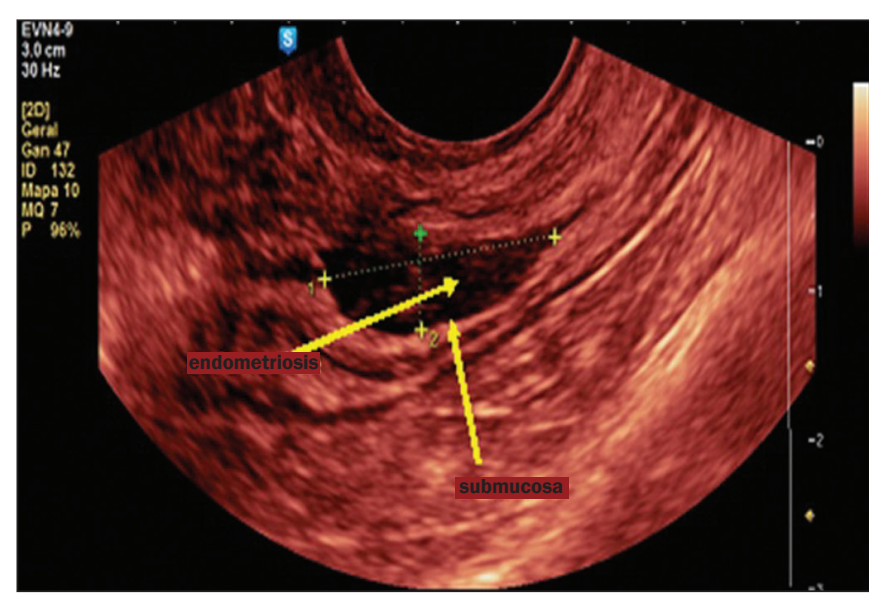

Figure 5. Sagittal image showing hypoechoic infiltration of the serosa and the muscularis propria. The hyperechoic submucosa is intact.

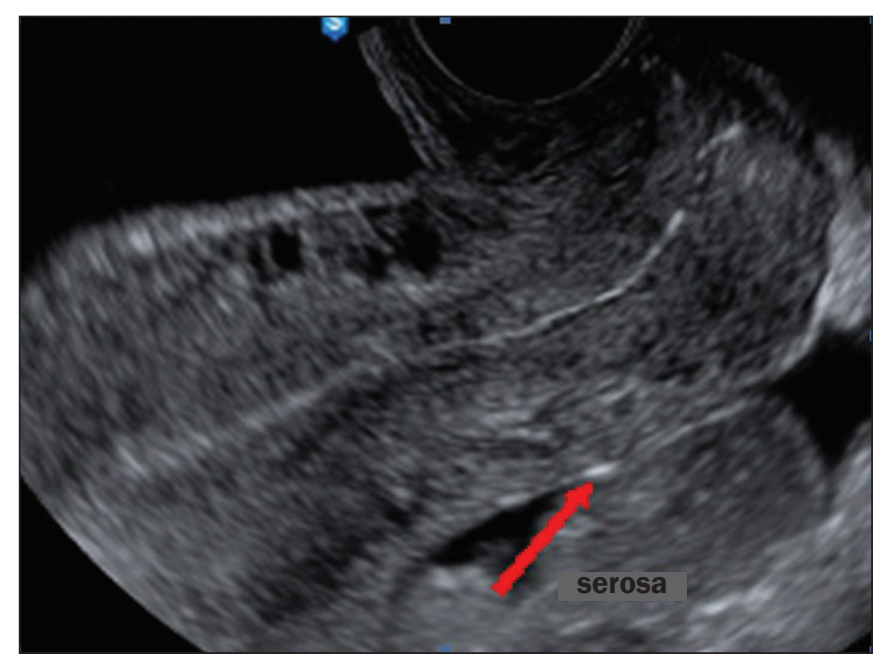

Figure 6. Posterior uterine serosa, longitudinal view.

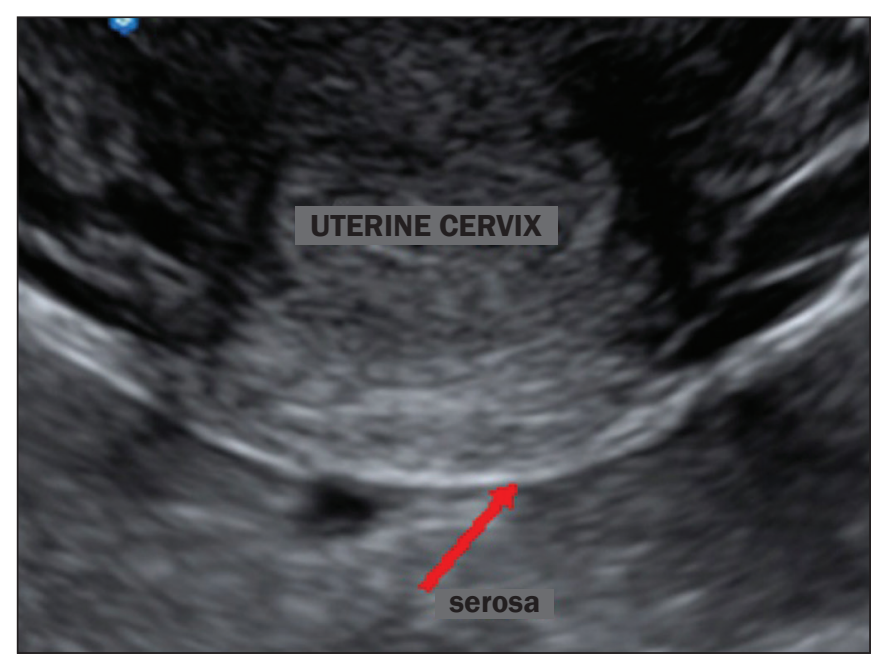

Figure 7. Posterior uterine serosa, transverse view.

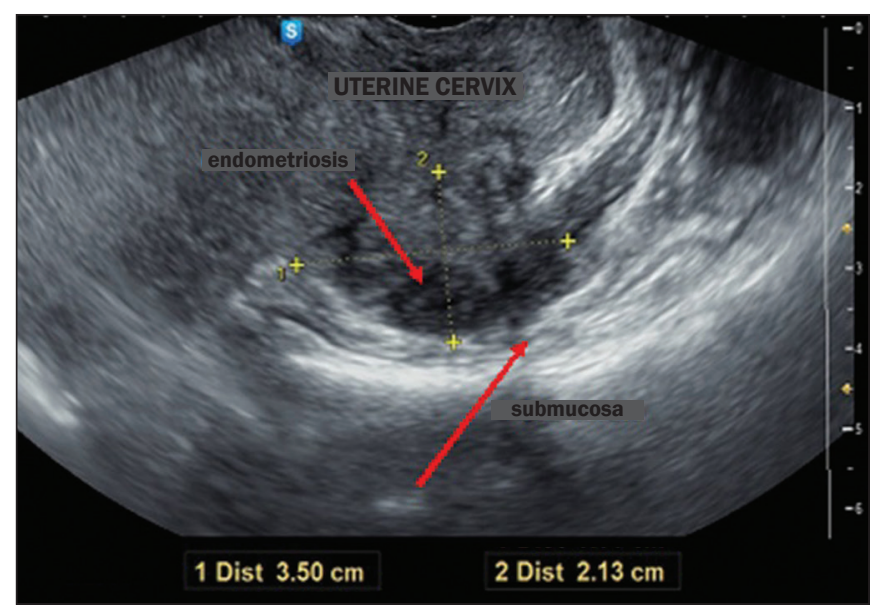

Figure 8. Hypoechoic solid nodule, with irregular margins, infiltrating the cervix and the muscularis propria.

That is why evaluation of the urinary tract is recommended when there is suspicion of deep infiltrating endometriosis, particularly if there are nodules measuring more than $3 \mathrm{~cm}$ in the rectovaginal septum ${ }^{(13)}$. 
Posterior cervical lesions are infiltrating and hypoechoic, and they interrupt the normal echogenic line representing the posterior uterine serosa (Figures 9 and 10).

\section{Endometriosis of the round ligament}

For endometriosis of the round ligament, the main differential diagnosis is subserosal leiomyoma. In Figure 11 we see small hypoechoic lesions in the round ligament, which was described as endometrioma because the patient had other endometrial lesions, including intestinal lesions and a previously diagnosed endometrioma on the right. As shown in our study, lesions such as these are typically described as endometriomas. Specifically in this case, the patient had endometriotic lesions at other anatomical sites.

An ovarian endometrioma is a marker for pelvic endometriosis and rarely occurs in isolation. Therefore, it should be emphasized that in the clinical context of an ovarian endometrioma, TVUS should be used in order to investigate the extent of the disease by checking for other endometrial lesions, with the objective of choosing the most appropriate means of treating the pain and infertility of the patient, rather than focusing solely on the ovarian lesion ${ }^{(14)}$.

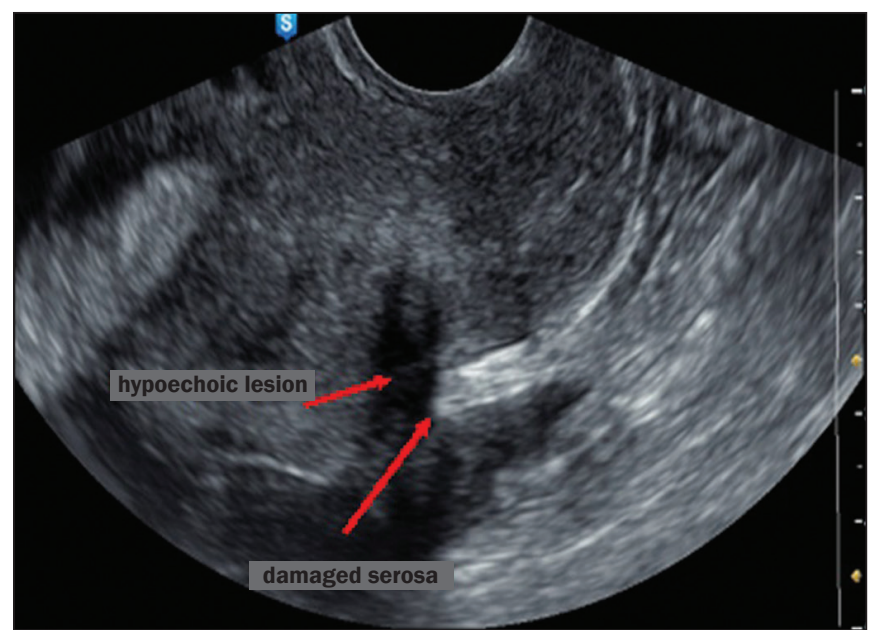

Figure 9. Irregular hypoechoic lesion bisecting the hyperechoic line that represents the posterior uterine serosa in the cervical region.

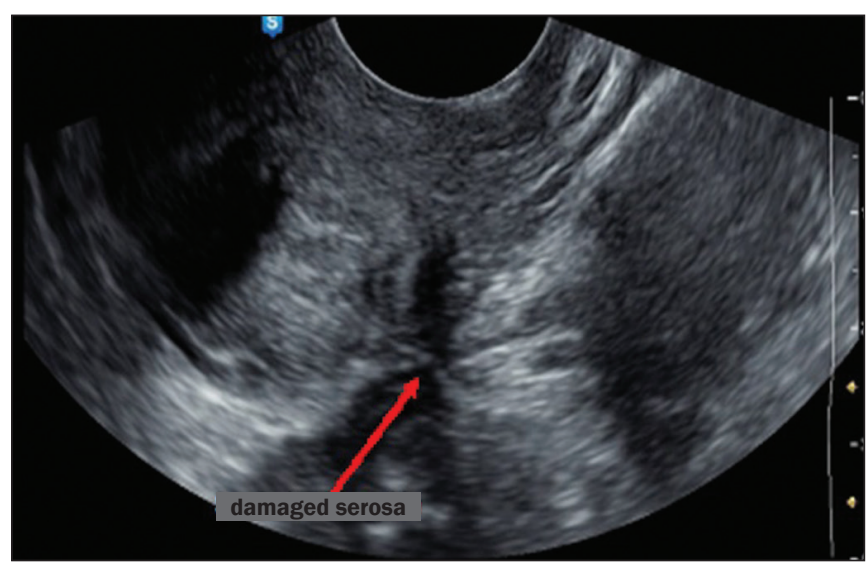

Figure 10. Irregular hypoechoic lesion, identified as an endometrial lesion, in the posterior cervical region.

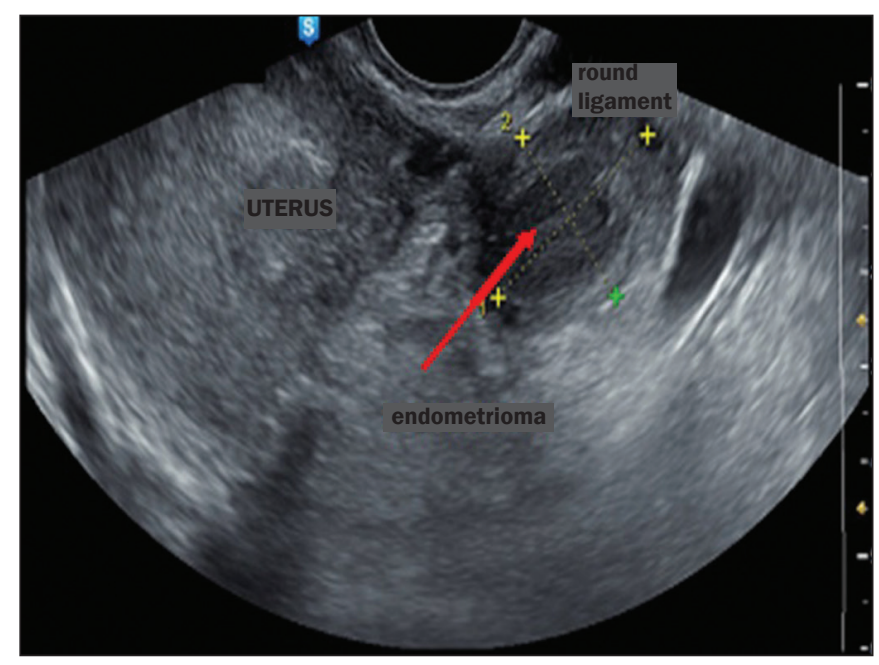

Figure 11. Hypoechoic lesion in the round ligament.

\section{Endometrioma in the bladder}

TVUS is a precise technique for detecting endometrial nodules in the bladder wall of patients with urinary symptoms. Figures 12 and 13 depict a case characterized by a hypoechoic nodular lesion located between the anterior wall of the uterus and the bladder. The patient became pregnant soon after the examination, and the finding was confirmed during a cesarean section.

\section{Adenomyosis}

Adenomyosis is defined as the presence of endometrial glands and stroma at the level of the uterine muscle layer. The ectopic presence of such tissue induces hypertrophy and hyperplasia of the surrounding myometrium, resulting in an increase in the uterine volume. In most cases, the ectopic endometrial tissue is found in the myometrium, rather than in its normal location (i.e., the endometrium). However, should the endometrial tissue be located relatively far from the normal endometrium, this would constitute a subserosal adenomyosis ${ }^{(15)}$, which can

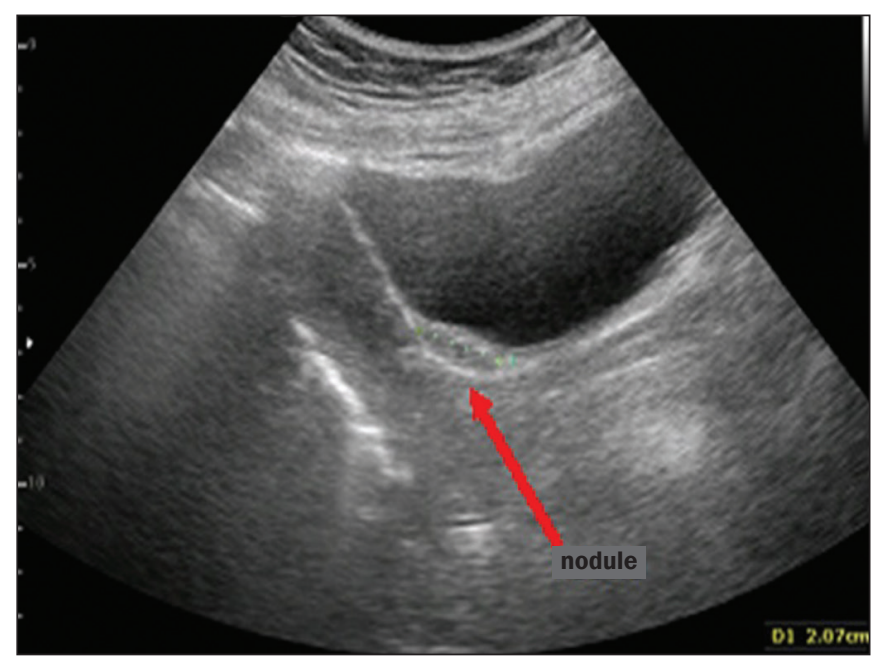

Figure 12. An endometriotic nodule in the vesicouterine pouch, creating a bulge in the bladder wall that is easily visualized on transabdominal ultrasound. 


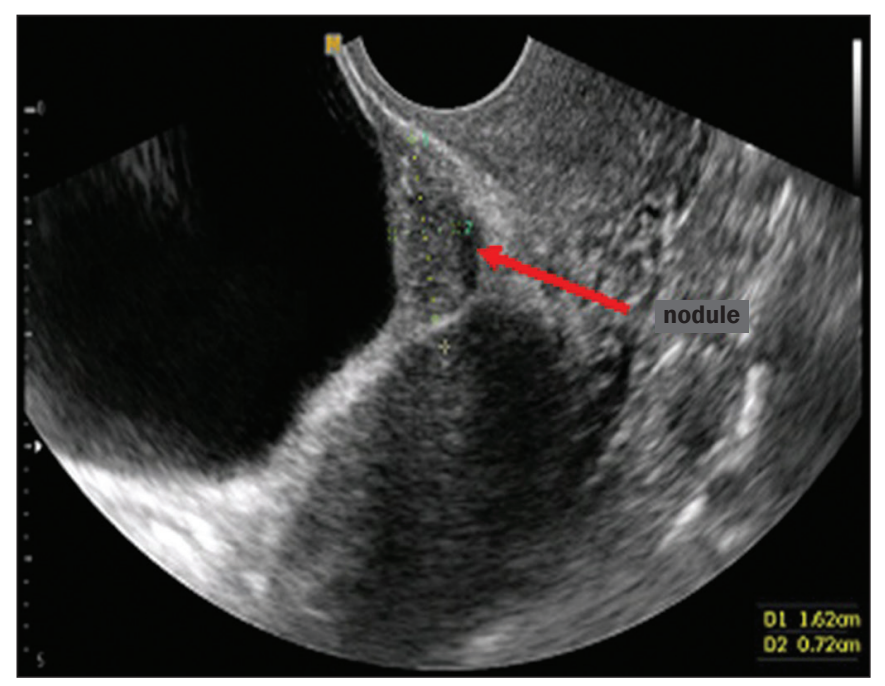

Figure 13. On TVUS, the filling of the bladder facilitates the visualization of a hypoechoic nodule between the bladder and the anterior wall of the uterus.

occasionally present as hemoperitoneum due to a ruptured cyst ${ }^{(16)}$.

Figure 14 shows a typical case of adenomyosis, presenting as a heterogeneous myometrium, with acoustic shadowing in a fan shape ("sun ray appearance") with asymmetry between the walls of the uterus. Van den Bosch et al. ${ }^{(17)}$ described adenomyosis as the transformation of endometrium into myometrium, albeit poorly defined, with asymmetrical walls, containing a vascularized nodule.

\section{CONCLUSION}

The ultrasound findings described above demonstrate the usefulness of ultrasound in diagnosing endometriosis. This study corroborates the findings of other recent studies, which advocate the use of TVUS as the first-line examination for women suspected of having endometriosis, by virtue of its simplicity, good tolerability, and accuracy. In addition, clinicians should be attentive to symptoms suggestive of the disease and ultrasound technicians should undergo specific training for endometriosis imaging.

\section{REFERENCES}

1. Boaventura CS, Rodrigues DP, Silva OAC, et al. Evaluation of the indications for performing magnetic resonance imaging of the female pelvis at a referral center for cancer, according to the American College of Radiology criteria. Radiol Bras. 2017;50:1-6.

2. Alves I, Cunha TM. Clinical importance of second-opinion interpretations by radiologists specializing in gynecologic oncology at a tertiary cancer center: magnetic resonance imaging for endometrial cancer staging. Radiol Bras. 2018;51:26-31.

3. Duarte AL, Dias JL, Cunha TM. Pitfalls of diffusion-weighted imaging of the female pelvis. Radiol Bras. 2018;51:37-44.

4. Godoy LL, Torres US, D'Ippolito G. Subinvolution of the placental site associated with focal retained products of conception and placenta accreta mimicking uterine arteriovenous malformation on CT and MRI: a lesson to be learned. Radiol Bras. 2018;51:135-6.

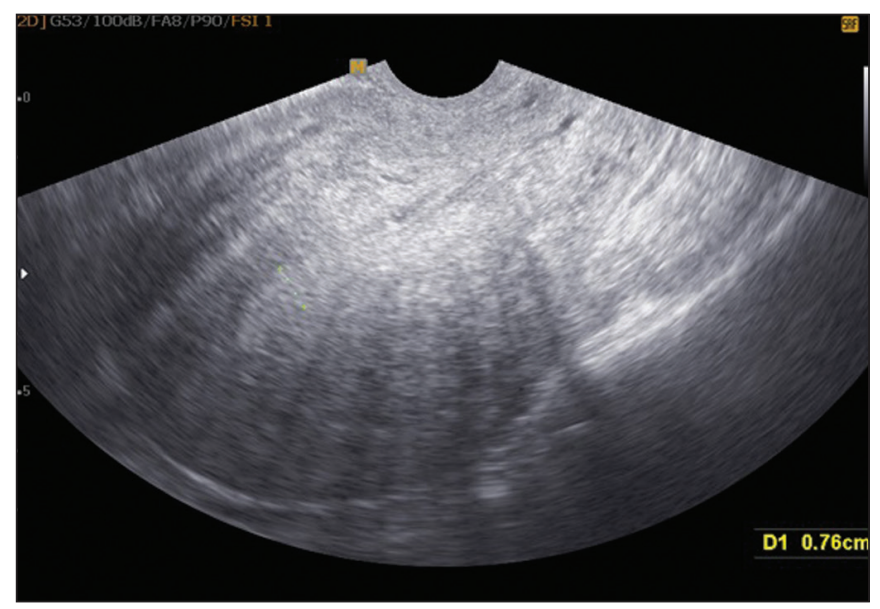

Figure 14. Adenomyosis, as indicated by the acoustic shadowing in a fan shape ("sun ray appearance").

5. Rodrigues PSC, Silva TSAM, Souza MMT. Endometriose: importância do diagnóstico precoce e atuação da enfermagem para o desfecho do tratamento. Revista Pró-UniverSUS. 2015;6:13-6.

6. Dancet EAF, D'Hooghe TM, Sermeus W, et al. Patients from across Europe have similar views on patient-centred care: an international multilingual qualitative study in infertility care. Hum Reprod. 2012; 27:1702-11.

7. Arruda MS, Camargo MMA, Camargo Jr HSA, et al. Endometriose profunda: aspectos ecográficos. Femina. 2010;38:367-72.

8. Noventa M, Saccardi C, Litta P, et al. Ultrasound techniques in the diagnosis of deep pelvic endometriosis: algorithm based on a systematic review and meta-analysis. Fertil Steril. 2015;104:366-83.

9. Guerriero S, Condous G, van den Bosch T, et al. Systematic approach to sonographic evaluation of the pelvis in women with suspected endometriosis, including terms, definitions and measurements: a consensus opinion from the International Deep Endometriosis Analysis (IDEA) group. Ultrasound Obstet Gynecol. 2016;48:318-32.

10. Gonçalves MO, Dias JA Jr, Podgaec S, et al. Transvaginal ultrasound for diagnosis of deeply infiltrating endometriosis. Int J Gynaecol Obstet. 2009; 104:156-60.

11. Pires CR, et al. Endometriose. In: Pastore A. Ultrassonografia em ginecologia e obstetrícia. Rio de Janeiro, RJ: Revinter; 2006.

12. Chamié LP, Blasbalg R, Pereira RM, et al. Findings of pelvic endometriosis at transvaginal US, MR imaging, and laparoscopy. Radiographics. 2011;31:E77-100.

13. Donnez J, Nisolle M, Squifflet J. Ureteral endometriosis: a complication of rectovaginal endometriotic (adenomyotic) nodules. Fertil Steril. 2002;77:32-7.

14. Exacoustos C, Pizzo A, Morosetti G, et al. EP27.12: Endometrioma - the tip of a pelvic disease: TVS findings associated with an ovarian endometriosis. Ultrasound Obstet Gynecol. 2016;48(Special Issue):270-393.

15. Sakamoto A. Subserosal adenomyosis: a possible variant of pelvic endometriosis. Am J Obstet Gynecol. 1991;165:198-201.

16. Afonso MC, Castro C, Osório F, et al. Adenomiose: uma apresentação atípica. Acta Obstet Ginecol Port. 2014;8:297-9.

17. Van den Bosch T, Dueholm M, Leone FP, et al. Terms, definitions and measurements to describe sonographic features of myometrium and uterine masses: a consensus opinion from the Morphological Uterus Sonographic Assessment (MUSA) group. Ultrasound Obstet Gynecol. 2015;46:284-98. 